\title{
APLICAÇÃO DE LIPASE MICROBIANA NO TRATAMENTO DE RESÍDUOS OLEOSOS
}

\author{
L.F.F. CARVALHO ${ }^{1}$, P.R.M.B. ${ }^{2}$, M.S. SOARES JUNIOR ${ }^{3}$, G.L. CASTIGLIONI ${ }^{3}$ \\ ${ }^{1}$ Universidade Federal de Goiás, Setor de Engenharia de Alimentos \\ 2 Professora do Instituto Federal de Educação e Ciência do Estado de Goiás/IFG \\ ${ }^{3}$ Universidade Federal de Goiás, Professor da Escola de Agronomia \\ E-mail para contato: lara_francielle@yahoo.com.br; g_castigli@yahoo.com.br; \\ pablinemello@yahoo.com.br; ssoaresjr@hotmail.com
}

\begin{abstract}
RESUMO - O pré-tratamento enzimático de efluentes oleosos a partir de lipases vem sendo considerado como uma técnica promissora para reduzir o tempo de retenção destes efluentes na digestão anaeróbia. Neste sentido, o presente trabalho teve como objetivo a aplicação de lipase microbiana na hidrólise de efluente oleoso proveniente da industrialização de batatas fritas. A influência dos processos descontínuo e descontínuo alimentado foram avaliadas a partir da triplicata e a comparação de médias pelo teste de Tukey. A utilização do processo descontínuo permitiu a obtenção de resultados bastante satisfatórios para a hidrólise do efluente. Observou-se aumento da hidrólise durante 7 h (0,492 U.mL-1) e 1h (0,233 U.mL-1) de reação para os processos descontínuo e descontínuo alimentado, respectivamente. Durante a cinética de hidrólise do efluente verificou-se que a utilização do processos descontínuo apresentou maior potencial de tratamento do efluente industrial, proporcionando desta forma uma boa alternativa para minimizar o impacto ambiental ocasionado por este resíduo.
\end{abstract}

PALAVRAS-CHAVE: Lipase, Hidrólise, Resíduo.

\section{INTRODUÇÃO}

As lipases são enzimas usadas na catálise de algumas reações, como hidrólise, alcoolize e acidólise de glicerol, mas tem sido descoberto que as lipases também podem ser usadas como catalisadora nas reações de esterificação e transeterificação. As lipases apresentam aplicações promissoras no setor alimentício, agroquímico, óleoquímico e farmacêutico, proporcionando o crescimento de tecnologias para a síntese de novos compostos de grande importância comercial e ambiental.

O tratamento de efluentes por lipases é benéfico no âmbito social, por fazer parte de um desenvolvimento sustentável, pois estes são considerados agentes poluidores. A busca de novas alternativas de tratamento estaria agregando valor aos resíduos oleosos das indústrias de alimentos, que se encontram hoje sem nenhum valor. $O$ isolamento e utilização de microrganismos capazes de produzir lipase com capacidade de transesterificação pode contribuir significativamente para a produção de biodiesel, que substitui total ou parcialmente o óleo diesel de petróleo em motores ciclodiesel automotivos (como caminhões, tratores, camionetas, automóveis, etc) ou estacionários (geradores de eletricidade, calor, etc). Pode ser 
usado puro ou misturado ao diesel em diversas proporções, e seu uso levará a uma redução da dependência das importações de petróleo, a chamada "petrodependência".

Tendo em vista as observações mencionadas o presente trabalho teve como objetivo caracterizar a lipase de Burhkolderia cepacia quanto a temperatura e o $\mathrm{pH}$, bem como otimizar a reação de hidrólise enzimática do efluente proveniente de uma indústria de processamento de batata frita.

\section{METODOLOGIA DE TRABALHO}

\subsection{Lipase e efluente}

Os experimentos foram realizados utilizando lipase de Burkholderia cepacia BCALPS, Amano. O efluente industrial utilizado foi de uma indústria de processamento de batatas fritas.

\subsection{Atividade enzimática}

Alíquotas do meio reacional foram analisadas acerca da atividade lipolítica, conforme método descrito por Macedo, Park e Pastore (1997), com adaptações. Para a determinação da atividade lipolítica, $1 \mathrm{~mL}$ do meio reacional foi transferido para um erlenmeyer contendo 5 $\mathrm{mL}$ de água destilada nos tempos 0 (branco) e 30 min de reação. Os ácidos graxos liberados durante a reação foram titulados com solução de hidróxido de sódio $(\mathrm{NaOH}) \quad 0,01 \mathrm{~N}$ na presença de solução alcoólica de fenolftaleína a 1\%. A unidade de atividade de lipase foi definida como a quantidade de enzima capaz de liberar $1 \mu \mathrm{mol}$ de ácido graxo por minuto.

\subsection{Estudo da degradação de efluente pela lipase de Burkholderia cepacia}

A avaliação dos parâmetros experimentais foi realizada por meio de delineamento experimental fatorial fracionário $2^{6-2}$, com 18 experimentos. As variáveis independentes analisadas para o tratamento do efluente foram o pH, a concentração de enzima em relação ao efluente e o volume de goma arábica a 7\% utilizado (agente emulsificante), sendo a variável resposta o grau de hidrólise dos triacilglicerídeos. Os níveis utilizados foram 7,16; 7,50; 8,00; 8,50 e 8,84 para o $\mathrm{pH}, 0,013 ; 0,040,0,080 ; 0,120$ e $0,147 \mathrm{~g} \cdot \mathrm{mL}^{-1}$ para a concentração de enzima, 0,$00 ; 1,21 ; 3,00 ; 4,79$ e 6,00 $\mathrm{mL}$ para goma arábica $7 \% \mathrm{~m} / \mathrm{v}$, após $3 \mathrm{~h}$ de hidrólise.

As reações foram conduzidas em erlenmeyers com capacidade de $125 \mathrm{~mL}$, incubados a $37^{\circ} \mathrm{C}$, sob agitação em banho Maria. Nos tempos $0,30 \mathrm{~min}$, e posteriormente, a cada hora durante $8 \mathrm{~h}$ e finalmente a $24 \mathrm{~h}$, foram retiradas alíquotas das amostras, para acompanhamento da evolução da reação de hidrólise. O grau de hidrólise foi verificado por meio da quantificação do teor de ácidos graxos livres (Item 2.2).

Para a avaliação dos processos descontínuo e descontínuo alimentado utilizou-se a resposta obtida no processo de hidrólise dos triacilglicerídeos. Nos ensaios descontínuos foram adicionados $10 \mathrm{~mL}$ de solução composta por tampão fosfato, goma arábica, enzima e água destilada e $30 \mathrm{~mL}$ do efluente industrial, totalizando $40 \mathrm{~mL}$ em cada erlenmeyer. Nos ensaios descontínuos alimentados também foram adicionados de $10 \mathrm{~mL}$ solução composta por tampão fosfato, goma arábica, enzima e água destilada, porém com apenas $40 \%$ do volume total do efluente utilizado no regime descontínuo, totalizando $22 \mathrm{~mL}$ no início da reação de hidrólise em cada erlenmeyer. Os outros $60 \%$ do volume total do efluente foram adicionados gradativamente em volumes de $3 \mathrm{~mL}$ durante as seis primeiras horas da reação.

As reações foram conduzidas em erlenmeyers com capacidade de $125 \mathrm{~mL}$, incubados a $37^{\circ} \mathrm{C}$, sob agitação em banho Maria. Nos tempos 0, $30 \mathrm{~min}$, e posteriormente, a cada hora 
durante $8 \mathrm{~h}$ e finalmente em $24 \mathrm{~h}$, foram retiradas alíquotas das amostras, para acompanhamento da evolução da reação de hidrólise. O grau de hidrólise foi verificado por meio da quantificação do teor de ácidos graxos livres, utilizando método titulométrico (Item 2.2). A avaliação de ambos processos foi realizada em três repetições e a análise da atividade hidrolítica em triplicata. As médias foram comparadas pelo teste de Tukey a $5 \%$ de probabilidade.

\section{RESULTADO E DISCUSSÃO}

Os ensaios para verificar o efeito do $\mathrm{pH}$, da concentração de lipase e do agente emulsificante sobre o efluente, foram feitos a partir da evolução da hidrólise em função do tempo. A Figura 4 apresenta a evolução da atividade hidrolítica durante as $24 \mathrm{~h}$ de degradação do efluente pela lipase.

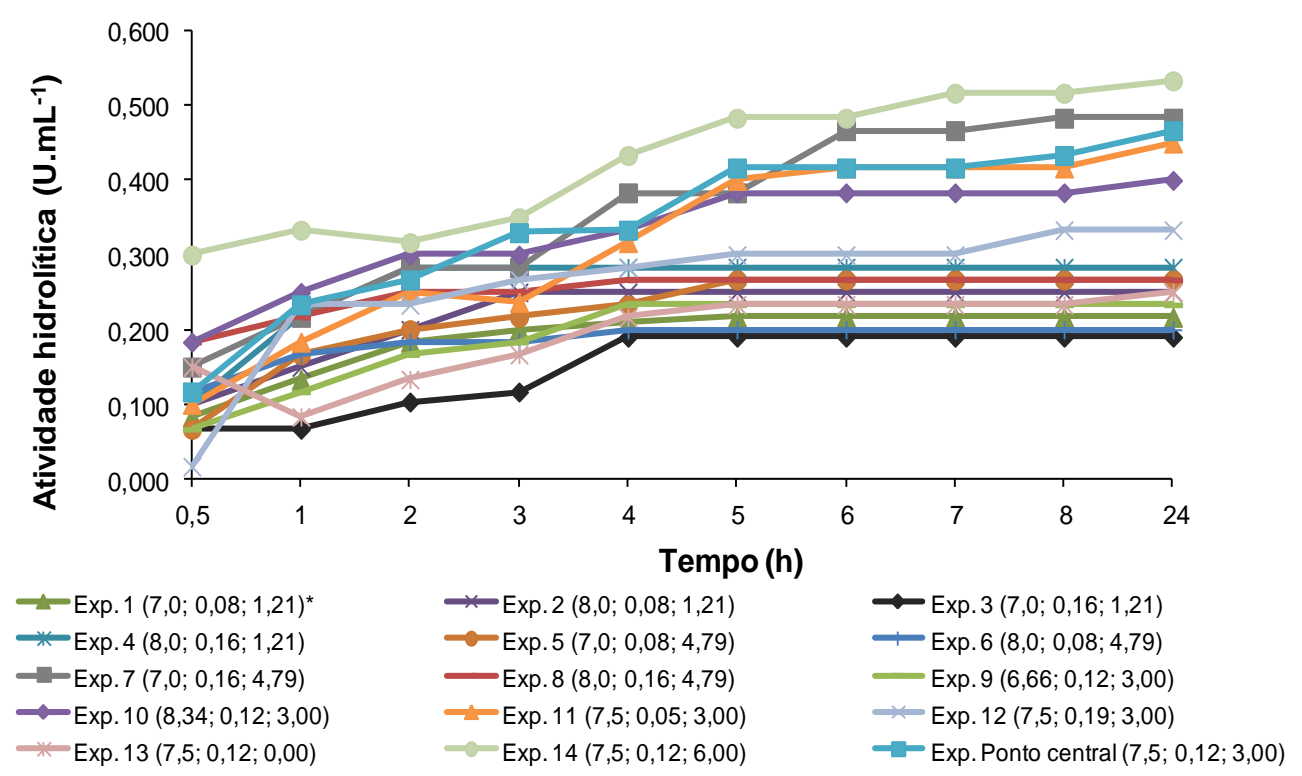

*Na qual: Exp n: número do experimento (pH; concentração de enzima [g.mL ${ }^{-1}$ ]; volume de goma arábica a $7 \%$ [mL]).

Figura 4 - Evolução da hidrólise do efluente industrial pela lipase durante $24 \mathrm{~h}$ de reação dos experimentos do delineamento experimental fracionário $2^{6-2}$

As atividades hidrolíticas mínima e máxima foram de 0,1900 e 0,4833 U.mL ${ }^{-1}$, respectivamente para o tempo de $24 \mathrm{~h}$. A atividade hidrolítica da lipase aumentou durante as 24 h de reação para os ensaios $2,7,10,11,14$ e ponto central, para os demais ensaios a partir de $4 \mathrm{~h}$ de reação o valor da atividade hidrolítica permaneceu praticamente constante, portanto, infere-se que houve hidrólise total dos triacilglicerídeos do efluente. A maior variação entre os ensaios foi observada após $3 \mathrm{~h}$ de hidrólise, indicando que a produção de ácidos graxos livres tendeu a estabilização após esse período. Os resultados para a atividade hidrolítica sobre o efluente em função do $\mathrm{pH}$, da concentração de enzima e do volume de goma arábica a 7\%, durante 3 h de reação estão apresentados na Tabela 3.

Os efeitos linear e quadrático do $\mathrm{pH}(\mathrm{p}=0,0332$ e $\mathrm{p}=0,0078$, respectivamente), quadrático da concentração de enzima $(\mathrm{p}=0,0129)$, linear e quadrático do volume de goma arábica $7 \%$ ( $\mathrm{p}=0,0197$ e $\mathrm{p}=0,0184$, respectivamente) e a interação do $\mathrm{pH}$ com goma arábica a $7 \%(\mathrm{p}=0,0252)$ foram significativos, enquanto os demais efeitos não foram significativos. 
Tabela 3 - Resultados de atividade hidrolítica para o delineamento experimental fatorial fracionário $2^{6-2}$. Onde [E] a concentração de enzima em g.mL $\mathrm{mL}^{-1} \mathrm{e}$ G o volume em $\mathrm{mL}$ de goma arábica $7 \% \mathrm{~m} / \mathrm{v}$, após $3 \mathrm{~h}$ de hidrólise

\begin{tabular}{ccccc}
\hline Ensaios & $\mathrm{pH}$ & {$[\mathrm{E}]$} & $\mathrm{GA}$ & $\begin{array}{c}\text { Atividade hidrolítica } \\
\left(\mathrm{U}_{\mathrm{mL}} \mathrm{m}^{-1}\right)\end{array}$ \\
\hline 1 & 7,50 & 0,040 & 1,21 & 0,2000 \\
2 & 8,50 & 0,040 & 1,21 & 0,2500 \\
3 & 7,50 & 0,120 & 1,21 & 0,1167 \\
4 & 8,50 & 0,120 & 1,21 & 0,2833 \\
5 & 7,50 & 0,040 & 4,79 & 0,2167 \\
6 & 8,50 & 0,040 & 4,79 & 0,1833 \\
7 & 7,50 & 0,120 & 4,79 & 0,2833 \\
8 & 8,50 & 0,120 & 4,79 & 0,2500 \\
9 & 7,16 & 0,080 & 3,00 & 0,1833 \\
10 & 8,84 & 0,080 & 3,00 & 0,3000 \\
11 & 8,00 & 0,013 & 3,00 & 0,2367 \\
12 & 8,00 & 0,147 & 3,00 & 0,2663 \\
13 & 8,00 & 0,080 & 0,00 & 0,1667 \\
14 & 8,00 & 0,080 & 6,00 & 0,3500 \\
15 & 8,00 & 0,080 & 3,00 & 0,3333 \\
16 & 8,00 & 0,080 & 3,00 & 0,3333 \\
17 & 8,00 & 0,080 & 3,00 & 0,3333 \\
18 & 8,00 & 0,080 & 3,00 & 0,3333 \\
\hline
\end{tabular}

$\mathrm{O} \mathrm{pH}(\mathrm{Q})$ foi a variável que mais produziu efeito nas respostas de hidrólise dos triacilglicerídeos do efluente, seguida da concentração de enzima (Q) e volume de goma arábica (Q). As influências foram negativas, indicando que o aumento do $\mathrm{pH}$, da concentração de enzima e do volume de goma arábica a partir de um ponto de máximo diminui a hidrólise dos efluente pela lipase de Burkhoderia cepacia. A influência quadrática desses parâmetros indica que existe um aumento na hidrólise do efluente até atingir um ponto de máximo e depois essa hidrólise diminui, ou seja, há um pH, concentração de enzima e volume de goma na qual a hidrólise do efluente é máxima ou ótima para determinadas condições de ensaio.

A partir da estimativa do efeito de cada variável foi gerado um modelo matemático completo significativo $(\mathrm{p}=0,0277)$, com coeficiente de determinação $\left(\mathrm{R}^{2}\right)$ de 0,8565 , coeficiente de variação de $14,89 \%$ e falta de ajuste significativa $(F A=0,0000)$. Porém, devido o quadrado médio do erro experimental ser baixo $\left(\mathrm{QM}=1,1769.10^{-17}\right)$, a falta de ajuste foi considerada aparente e o modelo foi ajustado (WASZCZYNSKYJ et al., 1981), o que significa que o modelo pode ser utilizado para fins preditivos.

A remoção do termo linear da concentração de enzima $(\mathrm{p}=0,3500)$ e dos termos de interação $\mathrm{pH}$ com concentração de enzima $(\mathrm{p}=0,2907)$ e de interação $\mathrm{pH}$ com goma arábica $(\mathrm{p}=0,1133)$ conferiu coeficiente de determinação ajustado $\left(\mathrm{R}_{\mathrm{aj}}^{2}\right)$ menor que $\mathrm{o}$ do modelo completo, assim, o mesmos foram considerados relevantes e então, manteve-se o modelo completo com coeficiente de determinação ajustado de 0,7079 . Os coeficientes de regressão de cada termo do modelo completo foram apresentados na Tabela 4.

A Equação 2 representa o modelo matemático completo, representando a atividade hidrolítica de degradação do efluente $(\mathrm{AH})$ em função do $\mathrm{pH}\left(\mathrm{X}_{1}\right)$, da concentração de enzima $\left(\mathrm{X}_{2}\right)$, do volume de goma arábica $7 \%\left(\mathrm{X}_{3}\right)$ e interações $\mathrm{pH} /[\mathrm{E}]\left(\mathrm{X}_{4}\right), \mathrm{pH} / \mathrm{GA}\left(\mathrm{X}_{5}\right)$ e $[\mathrm{E}] / \mathrm{GA}$ $\left(\mathrm{X}_{6}\right)$. Os termos destacados em negrito referem-se as variáveis estatisticamente significativas $(\mathrm{p} \leq 0,05)$. 
Tabela 4 - Coeficientes de regressão do modelo ajustado da atividade hidrolítica para o delineamento experimental fatorial fracionário $2^{6-2}$

\begin{tabular}{lcccccc}
\hline $\begin{array}{c}\text { Fontes de } \\
\text { variação }\end{array}$ & $\begin{array}{c}\text { Coef. de } \\
\text { regressão }\end{array}$ & $\begin{array}{c}\text { Erro } \\
\text { padrão }\end{array}$ & t (11) & p-valor & $\begin{array}{c}\text { Lim. Conf. } \\
-95 \%\end{array}$ & $\begin{array}{c}\text { Lim. Conf. } \\
+95 \%\end{array}$ \\
\hline Média & 0,032699 & 0,0064 & 5,11 & $0,00034^{* *}$ & 0,0186 & 0,0468 \\
pH (L) & $-0,018371$ & 0,0035 & $-5,29$ & $0,00026^{* *}$ & $-0,0260$ & $-0,0107$ \\
pH (Q) & 0,011612 & 0,0036 & 3,22 & $0,00822^{* *}$ & 0,0037 & 0,0196 \\
[E] (L) & 0,011433 & 0,0035 & 3,29 & $0,00716^{* *}$ & 0,0038 & 0,0191 \\
[E] (Q) & 0,008659 & 0,0036 & 2,40 & $0,03535^{*}$ & 0,0007 & 0,0166 \\
GA (L) & 0,004101 & 0,0035 & 1,18 & $0,26203^{\text {ns }}$ & $-0,0035$ & 0,0118 \\
GA (Q) & 0,008659 & 0,0036 & 2,40 & $0,03535^{*}$ & 0,0007 & 0,0166 \\
\hline
\end{tabular}

** significativo a $1 \%$. * significativo a 5\%. ns: não significativo. $\mathrm{R}^{2}=0,83562 . \mathrm{R}_{\mathrm{aj}}=0,74595$.

$$
\begin{aligned}
& A H=0,331+0,025 X_{1}-0,036 X_{1}^{2}+0,010 X_{2}-0,033 X_{2}^{2}+0,029 X_{3}-0,030 X_{3}^{2}+ \\
& +0,015 X_{4}-0,035 X_{5}+0,023 X_{6}
\end{aligned}
$$

A superfície de resposta e de curva de contorno do delineamento de degradação dos triacilglicerídeos do efluente estão apresentadas na Figura 5. A atividade hidrolítica máxima $\left(0,310 \mathrm{U} \cdot \mathrm{mL}^{-1}\right)$ foi observada quando o volume de goma arábica a $7 \%$ foi fixado em $3 \mathrm{~mL}$, entre o pH de 7,47 a 7,92 e concentração de enzima de 0,111 a 0,148.

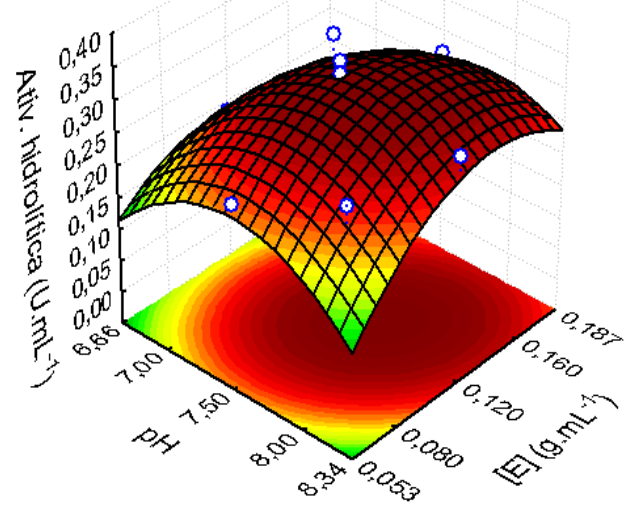

(a)

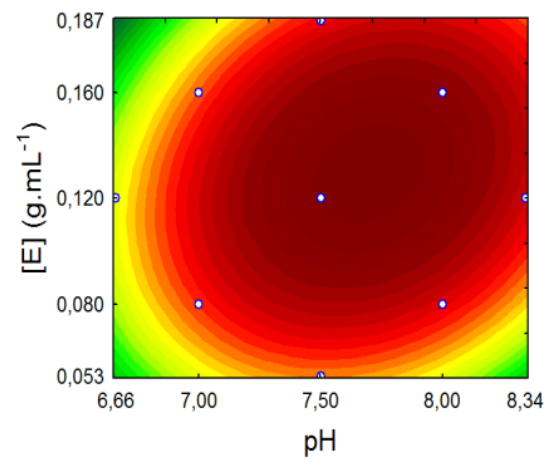

(b)

Figura 5 - Superfície de resposta (a) e curva de contorno (b) do delineamento experimental fatorial fracionário $2^{6-2}$, fixando o volume de goma arábica em $3 \mathrm{~mL}$.

Em trabalhos utilizando enzimas, quanto menor a concentração de lipase utilizada e maior a resposta obtida para a atividade hidrolítica, menor será o custo da operação em análise. No presente trabalho, a melhor resposta atividade hidrolítica foi obtida na área do gráfico com concentração de enzima de 0,111 a 0,148 g.mL ${ }^{-1}$. É mais vantajosa a utilização de menor quantidade de enzima, dentro desse intervalo ótimo, sem que ocorra redução da atividade hidrolítica, além de reduzir os custos do tratamento do efluente. Na literatura, resultados diferentes foram obtidos para a atividade hidrolítica em função da concentração de enzima. Valente et al. (2010), estudaram a pré-hidrólise da gordura de efluente da indústria de 
pescado pela lipase pura do fungo Penicillium simplicissimum nas concentrações de $0,2,0,5$ e $1,0 \% \mathrm{~m} / \mathrm{v}$ em processo descontínuo. A diferença na produção de ácidos graxos livres produzidos nos experimentos não foi significativa, apesar de ter aumentado com o teor de Penicillium simplicissimum na hidrólise, devido possivelmente, ao fato de haver produção e consumo simultâneos desses compostos no meio reacional (LEAL; FREIRE e SANT'ANNA JR., 2002). No presente trabalho, a concentração de enzima foi significativa no processo de hidrólise no tratamento do efluente.

Agentes emulsificantes, como a goma arábica, têm sido sistematicamente empregados em dosagens de atividade lipolítica quando se utilizam triacilglicerídeos de cadeia longa como substratos, não sendo considerados interferentes na hidrólise enzimática de lipídeos (MENDES; CASTRO, 2004). O uso da goma arábica a 7\% como agente emulsificante obteve uma melhor resposta da atividade hidrolítica.

O desempenho insatisfatório na atividade enzimática observado em $\mathrm{pHs}$ maiores que 8,34 pode ser atribuído a rápida elevação do $\mathrm{pH}$ do meio reacional a valores maiores que 9,0, afastando-se assim, do pH ótimo de atuação da lipase de Burkholderia cepacia, resultando na redução da atividade hidrolítica da enzima. Em pHs menores que 6,66, possivelmente, houve também inibição da lipase, haja vista que estas atuam, preferencialmente, em pHs alcalinos ou próximos do neutro. Essas alterações podem estar relacionadas com possíveis mudanças conformacionais da enzima ou alterações no macroambiente, ou seja, na concentração do substrato, produto, íons hidrogênio e íons hidroxilas do meio reacional (SAID; PIETRO, 2004; FERNANDES, 2007). Nos estudos de Pereira, Castro e Furigo (2003) as porcentagens de hidrólise mais elevadas de efluentes de indústrias avícolas foram obtidas em $\mathrm{pH} \mathrm{7,}$ resultado que está de acordo com o obtido no presente trabalho.

A validação do modelo proposto foi realizada em triplicata. Foi estabelecido $X_{1}$ de 7,5 de $\mathrm{pH}, \mathrm{X}_{2}$ de 0,12 g. $\mathrm{mL}^{-1}$ de enzima comercial de Burkholderia cepacia, $\mathrm{X}_{3}$ de $3 \mathrm{~mL}$ de volume de goma arábica e $\mathrm{AH}_{\text {est }}$ (resposta estimada pelo modelo para atividade hidrolítica) de 0,310 U.mL ${ }^{-1}$. A resposta obtida experimentalmente (AH) foi de $0,330 \mathrm{U} \cdot \mathrm{mL}^{-1}$. O erro em relação ao modelo foi de $6,06 \%$, indicando que os resultados experimentais foram adequadamente ajustados ao modelo proposto.

Após obter a avaliação da hidrólise dos triacilglicerídeos do efluente analisou-se também o efeito do modo de operação do processo, descontínuo e descontínuo alimentado sobre a reação (Figura 6).

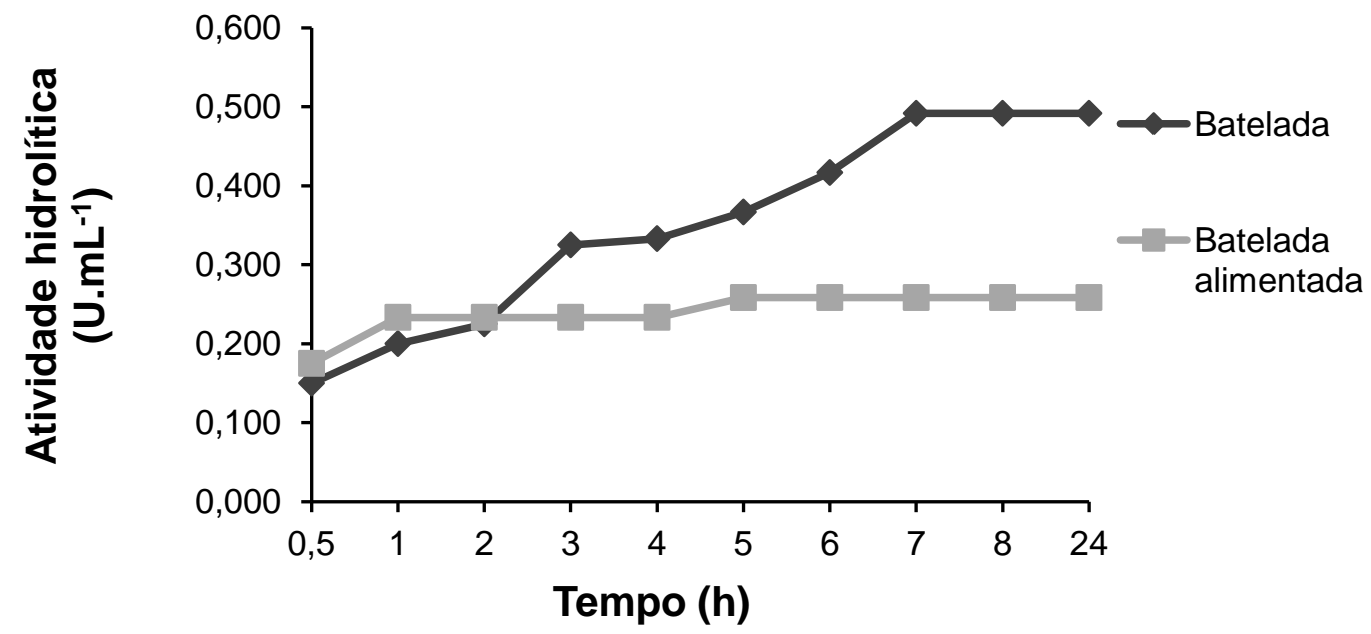

Figura 6 - Evolução da hidrólise do efluente industrial pela lipase de Burkholderia cepacia durante 24 $\mathrm{h}$ de reação, em processo descontínuo e descontínuo alimentado 
A utilização do processo descontínuo permitiu a obtenção de resultados bastante satisfatórios para a hidrólise do efluente. Houve aumento da atividade hidrólitica constantemente durante as sete primeiras horas de reação, sendo a máxima atividade hidrolítica encontrada de 0,492 U.mL ${ }^{-1}$. Entretanto, no processo descontínuo alimentado a reação de hidrólise foi vigorosa apenas na primeira hora, com atividade de $0,233 \mathrm{U} \cdot \mathrm{mL}^{-1}$. A partir de então, a variação na atividade hidrolítica ocorreu apenas depois de $4 \mathrm{~h}$ de reação $\left(0,258 \mathrm{U} \cdot \mathrm{mL}^{-1}\right)$, permanecendo estável até o final da processo, no tempo de $24 \mathrm{~h}$.

O modo de operação do processo, descontínuo e descontínuo alimentado, influenciou significativamente $(\mathrm{p} \leq 0,05)$ a reação hidrolítica dos triacilglicerídeos do efluente pela lipase de Burkholderia cepacia. Apenas no tempo $2 \mathrm{~h}$ de reação que as atividades hidróliticas dos triacilglicerídeos, pela lipase de Burkholderia cepacia, não foram consideradas estatisticamente significativas ( $p>0,05)$.

No processo descontínuo, o aumento da hidrólise ao longo das $24 \mathrm{~h}$ de reação, evidenciou outro aspecto importante, que o substrato não inibiu a enzima, mesmo em alta concentração. O processo descontínuo pode levar a baixos rendimentos e/ou produtividades, quando o substrato adicionado de uma só vez no início da reação exerce efeitos de inibição, ou repressão (CARVALHO; SATO 2001a). No caso desta pesquisa esse efeito não foi observado, pelo contrário, o processo descontínuo favoreceu consideravelmente a hidrólise dos triacilglicerídeos do efluente industrial quando comparada ao processo descontínuo alimentado. Portanto, para o tratamento do efluente, o processo descontínuo em $\mathrm{pH} \mathrm{7,5,}$ concentração de enzima de 0,12 g.mL $\mathrm{mL}^{-1}$ e 7,5\% de goma arábica e $3 \mathrm{~h}$ de reação de hidrólise foram as melhores condições para se obter a hidrólise dos triacilglicerídeos presentes no efluente.

\section{CONCLUSÃO}

$\mathrm{Na}$ caracterização das lipases presentes no extrato enzimático e da lipase de Burkholderia cepacia, os melhores resultados foram encontrados a $37^{\circ} \mathrm{C}$ e pH 8,0. As melhores condições para a hidrólise do efluente industrial estudado foram utilizando processo descontínuo, em $\mathrm{pH}$ 7,5 , concentração de enzima de 0,12 g. $\mathrm{mL}^{-1}, 7,5 \%$ de goma arábica a $7 \%$ e em tempo de reação de $3 \mathrm{~h}$, o que proporcionou maior hidrólise dos triacilglicerídeos.

\section{REFERÊNCIAS BIBLIOGRÁFICAS}

CARVALHO, J. C. M.; SATO, S. Fermentação descontínua. In: SCHMIDELL, W.; LIMA, U.; AQUARONE, E.; BORZANI, W. Biotecnologia Industrial. 2. ed. Brasil: Edgard Blucher, 2001. Cap. 9, p. 193-204.

CASTIGLIONI, G. L. Estudo da produção e utilização de lipase de Burkholderia cepacia na síntese enzimática de biodiesel. 2009. 180p. Tese (Doutorado em Engenharia de Alimentos) Departamento de Engenharia de Alimentos da Universidade Estadual de Campinas (Unicamp), Campinas, 2009.

FERNANDES, M. L. M. Produção de lipases por fermentação no estado sólido e sua utilização em biocatálise. 2007. 120p. Tese (Doutorado em Química) - Departamento de Química Orgânica da Universidade Federal do Paraná (UFP), Curitiba, 2007.

FREIRE, D. M. G. Seleção de microrganismos lipolíticos e estudo da produção de lipase por Penicillium restrictum. 1996. 174p. Tese (Doutorado em Ciências) - Departamento de 
Bioquímica do Instituto de Química da Universidade Federal do Rio de Janeiro (UFRJ), Rio de Janeiro, 1996.

LEAL, M. C. M. R.; FREIRE, D. M. G.; SANT'ANNA JR., G. L. Hydrolytic enzymes as coadjuvants in the anaerobic treatment of dairy wastewaters. Brazilian Journal Chemical Engineering, São Paulo, v. 19, n. 2, p. 175-180, 2002.

LEHNINGER, A. L. Princípios da Bioquímica, 2. ed. São Paulo: Savier, 1986.

MACEDO, G. A.; PARK, Y. K.; PASTORE, G. M. Partial purification and characterization of an extracellular lipase from a newly isolated strain of Geotrichum sp. Brazilian Journal of Microbiology, São Paulo, v. 28, p. 90-95, 1997.

MENDES, A. A.; CASTRO, H. F. Redução do teor de lipídeos presentes em efluentes das indústrias de produtos lácteos empregando lipases pancreáticas. Revista Saúde e Ambiente (Health and Environment Journal), Joinville, v. 5, n. 1, p. 31-39, 2004.

PADILHA, G. S. Caracterização, purificação e encapsulamento de lipase de Burkholderia cepacia, 2010. 126p. Tese (Doutorado em Engenharia Química) - Departamento de Engenharia Química da Universidade Estadual de Campinas (Unicamp), Campinas, 2010.

PARUL, J.; SULAKSHANA, J.; GUPTA, M. N. A microwave-assisted microassay for lipases. Analytical and Bioanalytical Chemistry, Washington, v. 381, p. 1480-

1482, 2005.

SAID, S.; PIETRO, R. C. L. R. Enzimas como agentes biotecnológicos. Ribeirão Preto: Legis Summa, 2004, 416 p.

SUPAKDAMRONGKUL, P.; BHUMIRATANA, A.; WIWAT, C. Characterization of an extracellular lipase from the biocontrol fungus, Nomuraea rileyi $\mathrm{MJ}$, and its toxicity toward Spodoptera litura. Journal of Invertebrate Pathology, Amsterdã, v. 105, p. 228-235, 2010.

SVENDSEN, A.; BORCH, K.; BARFOED, M.; NIELSEN, TB.; GORMSEN, E.; PATKAR, S. A. Biochemical properties of cloned lipases from the Pseudomonas family. Biochimica et Biophysica Acta, Amsterdã, v. 9, n. 17, p. 1259, 1995.

TAKEDA, Y.; AONO, R.; DOUKYU, N. Purification, characterization, and molecular cloning of organic-solvent-tolerant cholesterol esterase from cyclohexane-tolerant

Burkholderia cepacia strain ST-200. Extremophiles, Washington, v. 10, n. 4, p. 269-277, 2006.

TRAUB, P. C.; SCHMIDT-DANNERT, C.; SCHMITT, J.; SCHMID, R. D. Gene synthesis, expression in E. coli, and in vitro refolding of Pseudomonas sp. KWI 56 and Chromobacterium viscosum lipases and their chaperones. Applied Microbiology Biotechnology, Washington, v. 55, n. 2, p. 198-204, 2001.

VALENTE, A. M.; ALEXANDRE, V. M.; CAMMAROTA, M. C.; FREIRE, D. M. G. Préhidrólise enzimática da gordura de efluente da indústria de pescado objetivando o aumento da produção de metano. Ciência e Tecnologia de Alimentos, Campinas, v. 30, n. 2, p. 483-488, 2010.

WASZCZYNSKYJ, N.; RAO, C. S.; DA SILVA, R. S. F. Extraction of proteins from wheat bran: application of carbohydrases. Cereal Chemistry, Saint Paul, v. 58, n. 4, p. 264-266, 1981.

WANG, X.; YU, X.; XU, Y. Homologous expression, purification and characterization of a novel high-alkaline and thermal stable lipase from Burkholderia cepacia ATCC 25416. Enzyme and Microbial Technology, Amsterdã, v. 45, p. 94-102, 2009. 